\title{
AN APPLICATION OF THE ANALYTIC HIERARCHY PROCESS TO ENHANCING CONSENSUS IN MULTIAGENT DECISION MAKING
}

\author{
Antonio Maturo* \\ Department of Social Sciences \\ University of Chieti - Pescara \\ 66013, Chieti, ITALY \\ E-mail: amaturo@unich.it \\ Aldo G. S. Ventre \\ Department of Culture of the Project and Benecon Research Center \\ Faculty of Architecture \\ Second University of Napoli \\ 81031, Aversa, ITALY \\ E-mail: aldoventre@gmail.com
}

\begin{abstract}
Ranking alternatives is a central issue in multi-criteria and multi-person decision making. Each member of a committee of experts has his own knowledge-base and a current information in order to make decisions. We assume the committee adopt the AHP as the tool that each expert uses to construct the personal ranking of alternatives. As described and formalized in (Carlsson et al., 1992; Eklund et al., 2007; Maturo, and Ventre, 2008) each decision maker is represented by a point of the Euclidean space $\mathrm{R}^{\mathrm{m}}$, where the coordinates are the scores of the alternatives. Enhancing consensus in the group reduces to implementing a procedure that makes these points closer, so that they can be included in a suitably small neighborhood. In order to obtain consensus the more peripheral decision makers are invited by an impartial chairman, called the Demiurge, to modify their assessments. What seems to us worth to be considered is a further convergence procedure related to the weights of the criteria that in the first levels of the hierarchy induce the choices in the alternative set.
\end{abstract}

Keywords: multicriteria and multiperson decision making, AHP, consensus.

\section{Introduction}

An aspect qualifying the work of a decision making group and attributing strength to the reached decision is the size of the majority that supports the decision and the degree of the consensus built up in the group. We deal with a committee made of experts that form a group appointed to make a decision, more precisely a commission having the purpose to make a decision, sufficiently shared, having social or economical implications.

Let us suppose that the commission behave as a system to which the single experts provide inputs by means of their opinions, quantifiable judgments, that usually are modified during the discussions. Basically the modifications of the positions of the single experts are caused by a number of circumstances, such as the injection of new elements of information, a series of psychological factors, the use of tactics, to have resort to negotiation.

The system works in such a way that modified opinions tend to become shared opinions. This behaviour is softly led by a supervisor, or a chairman, we call also the Demiurge, whose task consists in monitoring

\footnotetext{
* Corresponding author
} 
the state of consensus procedure, promoting understanding, and maintaining the cohesion of the group. The chairman is a support at expert's disposal (Carlsson et al., 1992; Eklund et al., 2007; Maturo, and Ventre, 2008).

Sometimes a member A in the commission tries to change another member's B mind. As a result of this action one of the following behaviours may occur: member B radicalize his position, he refuses the attempt of A and moves away or more clearly distinguishes his own position from A's; member B accepts to change his position, closer to A's; member B does not change at all his position. It may happen that some decision maker in the group lie in a peripheral position, with respect to the dominant opinion, toward which a considerable number of decision makers is oriented, for instance, a majority is growing up neighbouring a position. At this state of the decision process the chairman intervenes describing positions in contrast, inviting, more or less implicitly, the peripheral decision makers to find elements of sharing and strengthen the intensity of consensus in the commission.

Usually the peripheral decision maker refuses to be marginalized and wants to participate in building the final decision: he asks for clarifying or modifying his opinion with the intention of cooperating in reaching a decision that could obtain a large consensus.

Let us assume that the individual opinions in the commission are quantifiable judgments, a set of alternative decisions is available to each expert, who is able to construct a ranking of the alternatives agreeing with his preference system.

It is worth to remark that any consensus reaching procedure, and, in particular, the previous assumption, is not an actual constraint, provided that an explicative paradigm is shared by all the members in the commission. In other words, the existence of the explicative paradigm is a necessary condition to search for consensus, given the possibility to activate argumentative persuasion (Feyerabend, 1975; Sciarra, 2006)

In this context an eligible decision making structure is expressed by Analytic Hierarchy Process (Saaty, 1980; Saaty, and Peniwati, 2007; Saaty, 2008). In fact, we assume that any decision maker uses AHP in order to construct his individual ranking of the alternatives on the basis of his own quantifiable judgments. In such a way, if the alternatives are in number of $\mathrm{m}$, then every decision maker individuates, or may be identified by, a point in a Euclidean m-dimensional space. The distance of two points, i. e. , the distance between the rankings of two experts, reveals the distance in their respective opinions. A perturbation of the weights in the criteria for an expert, due, for instance, to an intervention of the chairman, gives rise, in the individual hierarchical system, to an output that results in a perturbation of the rankings at the lower levels.

\section{A mathematical model of multicriteria and multiagent decision making}

Let $\mathrm{D}=\left\{\mathrm{d}_{1}, \mathrm{~d}_{2}, \ldots, \mathrm{d}_{\mathrm{k}}\right\}$ be the set of the decision makers, components of a committee, and let $\mathrm{A}=\left\{\mathrm{A}_{1}\right.$, $\left.\mathrm{A}_{2}, \ldots, \mathrm{A}_{\mathrm{m}}\right\}$ be the set of the alternatives. A set $\mathrm{K}=\left\{\mathrm{K}_{1}, \mathrm{~K}_{2}, \ldots, \mathrm{K}_{\mathrm{n}}\right\}$ of criteria is considered, in order to build a ranking of the alternatives.

Every decision maker $\mathrm{d}_{\mathrm{r}}, \mathrm{r}=1,2, \ldots, \mathrm{k}$, is requested to assign to every pair $\left(\mathrm{A}_{\mathrm{i}}, \mathrm{K}_{\mathrm{j}}\right)$ a score, $\mathrm{s}_{\mathrm{ij}}{ }^{(\mathrm{r})}$ that expresses to what extent the alternative $A_{i}$ satisfies the criterion $K_{j}$. Scores $s_{i j}{ }^{(r)}$ may be real numbers or fuzzy numbers as meanings attached to terms of a linguistic variable (Zadeh, 1975a).

If the scores are real numbers, we assume the constraints:

$$
\begin{gathered}
0 \leq \mathrm{s}_{\mathrm{ij}}{ }^{(\mathrm{r})} \leq 1, \\
\mathrm{~s}_{1 \mathrm{j}}{ }^{(\mathrm{r})}+\mathrm{s}_{2 \mathrm{j}}{ }^{(\mathrm{r})}+\ldots+\mathrm{s}_{\mathrm{mj}}{ }^{(\mathrm{r})}=1 .
\end{gathered}
$$

While, if the scores are fuzzy numbers, we assume the constraints:

$$
\sup \left(\mathrm{s}_{\mathrm{ij}}^{(\mathrm{r})}\right) \subseteq[0,1]
$$




$$
\operatorname{cor}\left(\mathrm{s}_{1 \mathrm{j}}{ }^{(\mathrm{r})}\right)+\operatorname{cor}\left(\mathrm{s}_{2 \mathrm{j}}{ }^{(\mathrm{r})}\right)+\ldots+\operatorname{cor}\left(\mathrm{s}_{\mathrm{mj}}{ }^{(\mathrm{r})}\right) \supseteq 1
$$

where, for every fuzzy number $u, \sup (u)$ is the support of $u$ and cor(u) is the core (Klir, and Yuan, 1995). If all $\mathrm{s}_{\mathrm{ij}}{ }^{(\mathrm{r})}$ are simple fuzzy numbers, i.e., the core of every fuzzy number is a singleton, then (2.4) reduces to the equality:

$$
\operatorname{cor}\left(\mathrm{s}_{1 \mathrm{j}}{ }^{(\mathrm{r})}\right)+\operatorname{cor}\left(\mathrm{s}_{2 \mathrm{j}}{ }^{(\mathrm{r})}\right)+\ldots+\operatorname{cor}\left(\mathrm{s}_{\mathrm{mj}}{ }^{(\mathrm{r})}\right)=1 .
$$

We assume that numbers $\mathrm{s}_{\mathrm{ij}}(\mathrm{r})$ and $\operatorname{cor}\left(\mathrm{s}_{\mathrm{ij}}{ }^{(\mathrm{r})}\right)$ in formulae (2.2) and (2.5) are obtained with the AHP procedure (Saaty, 1980; Saaty, and Peniwati, 2007; Saaty, 2008).

Now our aim is to implement an algorithm in order to:

(a) (aggregation with respect to criteria) aggregate, for every decision maker $\mathrm{d}_{\mathrm{r}}$ and for every alternative $A_{i}$, the judgments $s_{i j}{ }^{(r)}, j=1,2, \ldots, n$, in order to obtain a unique global judgment $\sigma_{i}^{(r)}$ of $d_{r}$ on $A_{i}$. The value $\sigma_{i}^{(r)}$ represents to what extent the alternative $A_{i}$ satisfies the criteria in the opinion of $\mathrm{d}_{\mathrm{r}}$;

(b) (control of consensus) control if the majority of the vectors $\sigma^{(\mathrm{r})}=\left(\sigma_{1}{ }^{(\mathrm{r})}, \sigma_{2}{ }^{(\mathrm{r})}, \ldots, \sigma_{\mathrm{m}}{ }^{(\mathrm{r})}\right)$ are sufficiently close one another with respect to a given metric;

(c) (aggregation with respect to decision makers) if the result of the control is positive, aggregate the scores $\sigma_{\mathrm{i}}^{(\mathrm{r})}, \mathrm{r}=1,2, \ldots, \mathrm{k}$, of all the decision makers, in order to obtain, for every alternative $\mathrm{A}_{\mathrm{i}}$, a unique global score $\sigma\left(\mathrm{A}_{\mathrm{i}}\right)$;

(d) (activation of consensus) if the result of the control is negative, activate a procedure for modifying the judgments of the more peripheral decision makers, in order that their score vectors approach the others, and then return to step (a).

It is worth remarking that, if consensus has been reached at step (b), then the authoritativeness of the judgment of the committee depends on the strength of the majority.

Recall that the procedure to get $\sigma\left(\mathrm{A}_{\mathrm{i}}\right)$ is coordinated by an impartial chairman, called the Demiurge, that utilizes mathematical aggregation algorithms and psychological techniques in order to obtain highest consensus among the experts.

\section{A dynamic AHP procedure to enhancing consensus}

Every expert $d_{r}$ is requested to assign his weights $\mathrm{w}_{j}{ }^{(r)}$ to the criteria $\mathrm{K}_{\mathrm{j}}$ 's, with the conditions:

$$
0 \leq \mathrm{w}_{\mathrm{i}}{ }^{(\mathrm{r})} \leq 1 \text { and } \mathrm{w}_{1}{ }^{(\mathrm{r})}+\mathrm{w}_{2}{ }^{(\mathrm{r})}+\ldots+\mathrm{w}_{\mathrm{n}}{ }^{(\mathrm{r})}=1 .
$$

He computes his global score $\sigma_{i}^{(r)}$ of the alternative $\mathrm{A}_{\mathrm{i}}$ by means of a given aggregation function, with domain $[0,1]^{\mathrm{n}}$, codomain $[0,1]$, and increasing with respect to every variable. Let :

$$
\mathrm{g}_{\mathrm{r}}:\left(\mathrm{x}_{1}, \mathrm{x}_{2}, \ldots, \mathrm{x}_{\mathrm{n}}\right) \in[0,1]^{\mathrm{n}} \rightarrow[0,1]
$$

be the aggregation function.

We assume the weights $\mathrm{w}_{\mathrm{i}}{ }^{(\mathrm{r})}$ be obtained applying the Analytic Hierarchy Process (Saaty, 1980; Saaty, and Peniwati, 2007: Saaty 2008) and the global score $\sigma_{i}^{(r)}$ is given by the formula:

$$
\sigma_{\mathrm{i}}{ }^{(\mathrm{r})}=\mathrm{g}_{\mathrm{r}}\left(\mathrm{W}_{1}{ }^{(\mathrm{r})} \mathrm{s}_{\mathrm{i} 1}{ }^{(\mathrm{r})}, \mathrm{w}_{2}{ }^{(\mathrm{r})} \mathrm{s}_{\mathrm{i} 2}{ }^{(\mathrm{r})}, \ldots, \mathrm{w}_{\mathrm{n}}{ }^{(\mathrm{r})} \mathrm{s}_{\mathrm{in}}{ }^{(\mathrm{r})}\right) .
$$


The simplest and more used aggregation function is addition (Carlsson et al., 1992; Eklund et al., 2007):

$$
\mathrm{g}_{\mathrm{r}}\left(\mathrm{x}_{1}, \mathrm{x}_{2}, \ldots, \mathrm{x}_{\mathrm{n}}\right)=\mathrm{x}_{1}+\mathrm{x}_{2}+\ldots+\mathrm{x}_{\mathrm{n}} .
$$

If the $\mathrm{s}_{\mathrm{ij}}^{(\mathrm{r})}$ are real numbers, then conditions $(2.1)$ and (3.1) assure that the sum belongs to [0, 1$]$. Moreover, from (2.3) and (3.1) if the $\mathrm{s}_{\mathrm{ij}}^{(\mathrm{r})}$ are fuzzy numbers the sum is contained in $[0,1]$.

We assume in the sequel that the aggregation function satisfies at least the following reasonable requirements:

(a) (boundary condition) $\mathrm{g}_{\mathrm{r}}\left(\mathrm{x}_{1}, \mathrm{x}_{2}, \ldots, \mathrm{x}_{\mathrm{n}}\right)=0$;

(b) (symmetry) for every permutation $\{\mathrm{i} 1,12, \ldots$, in $\}$ of $\{1,2, \ldots, \mathrm{n}\}$,

$$
\mathrm{g}_{\mathrm{r}}\left(\mathrm{x}_{1}, \mathrm{x}_{2}, \ldots, \mathrm{x}_{\mathrm{n}}\right)=\mathrm{g}_{\mathrm{r}}\left(\mathrm{x}_{\mathrm{i} 1}, \mathrm{x}_{\mathrm{i} 2}, \ldots, \mathrm{x}_{\mathrm{in}}\right)
$$

As an alternative to the sum we can adopt any t-conorm $\oplus$, that is, an operation on $[0,1]$ that is associative, commutative, and has 0 as neutral element. Because of these features a t-conorm $\oplus$ seems to be a good aggregation function. In particular properties (a) and (b) are fulfilled. As the sum is in [0, 1], it coincides with the truncated sum, the particular t-conorm $\oplus$ defined as $a \oplus b=\min \{a+b, 1\}$.

Of course, among the t-conorms, it would be preferable to choose the ones fulfilling further desirable conditions, such as continuity and Archimedean property (Weber, 1984).

Formulae alternative to the (3.3) are obtained by replacing products $\mathrm{w}_{\mathrm{j}}^{\left({ }^{(\mathrm{r})}\right.} \mathrm{s}_{\mathrm{ij}}^{(\mathrm{r})}$ with $\mathrm{w}_{\mathrm{j}}^{(\mathrm{r})} \otimes \mathrm{s}_{\mathrm{ij}}{ }^{(\mathrm{r})}$, where $\otimes$ is a suitable t-norm, that is, an operation on $[0,1]$ that is associative, commutative, having 1 as neutral element.

It is worth noting that if $\otimes$ is a sub-multiplicative t-norm, i.e., $w_{j}^{(r)} \otimes s_{i j}^{(r)} \leq w_{j}^{(r)} s_{i j}^{(r)}$, then the sum (3.4) belongs to $[0,1]$ and coincides with the truncated sum.

If both a t-norm $\otimes$ and a t-conorm $\oplus$ are involved in the same aggregation, then suitable relations between them should be satisfied, e.g., $\otimes$ and $\oplus$ be conjugate (Weber, 1984).

\subsection{A geometrical point of view}

In order to use a model that allows us to introducing monitoring and, possibly, manipulating a dynamics in the positions of the experts, let us identify the single decision makers with points of the space $\mathrm{R}^{\mathrm{m}}$ of alternatives. So, if the scores are real numbers, then each expert $d_{r}$ can be represented with the point $P_{r}=$ $\left(\sigma_{i}^{(r)}, i=1,2, \ldots, m\right)$ of $R^{m}$.

From the conditions (a) and (b) on the aggregation function $g_{r}$, it follows that every point $P_{r}$ belongs to the hypercube $[0,1]^{\mathrm{m}}$. Moreover, if operation $\mathrm{g}_{\mathrm{r}}$ is addition, and the scores are real numbers, then conditions (2.1), (2.2), and (3.1) imply that points $\mathrm{P}_{\mathrm{r}}$ are in the hyperplane:

$$
\mathrm{y}_{1}+\mathrm{y}_{2}+\ldots+\mathrm{y}_{\mathrm{m}}=1 \text {. }
$$

If a metric $\mu$ is introduced in $\mathrm{R}^{\mathrm{m}}$, then the Demiurge uses $\mu$ as a tool for evaluating the consensus among the decision makers: smaller are distances, greater is the consensus. If he believes the degree of consensus not acceptable, then he activates a procedure for enhancing it. Otherwise, if he recognizes that consensus has reached a satisfactory level, then applies some mathematical formulae for aggregating the opinions of the experts. In this framework, some formulae and algorithms are introduced and studied in (Carlsson, et al., 1992; Eklund, et al., 2007; Maturo, and Ventre, 2008; Maturo, et al., 2006).

For sake of simplicity from now on, in the present Sec., we assume scores are real numbers and the aggregation function is the sum. In one of the next sections we consider also a more general ambit. 


\subsection{A procedure for activating consensus}

Let a number $\alpha$ in the interval $[0,1]$ be given. We say that there is consensus of level 1- $\alpha$ between two decision makers $\mathrm{d}_{\mathrm{r}}$ and $\mathrm{d}_{\mathrm{s}}$ if $\mu\left(\mathrm{P}_{\mathrm{r}}, \mathrm{P}_{\mathrm{s}}\right)<\alpha$, where $\mathrm{P}_{\mathrm{r}}$ and $\mathrm{P}_{\mathrm{s}}$ are the points of $\mathrm{R}^{\mathrm{m}}$ representative of $\mathrm{d}_{\mathrm{r}}$ and $\mathrm{d}_{\mathrm{s}}$, respectively.

We define consensus sphere of $d_{r}$ the set of all decision makers $d_{s}$ such that $\mu\left(P_{r}, P_{s}\right) \leq \alpha$.

If $\mathrm{D}^{*}$ is a subset of $\mathrm{D}$ with at least two elements, consensus in $\mathrm{D}^{*}$ means that, for every $\mathrm{d}_{\mathrm{r}} \in \mathrm{D}^{*}$, the closed ball with centre $P_{r}$ and radius $\alpha$ contains all the points representative of the elements of $D^{*}$. In other words, we have consensus in $\mathrm{D}^{*}$ iff the consensus sphere of any element of $\mathrm{D}^{*}$ contains all the points representative of the elements of $\mathrm{D}^{*}$. A sufficient condition to have consensus in $\mathrm{D}^{*}$ is that there exists a closed ball with radius $\alpha / 2$ containing all the elements of $\mathrm{D}^{*}$. If there is consensus on $\mathrm{D}^{*}$ we say that $\mathrm{D}^{*}$ is a consensus set.

Finally, sufficient consensus means that there is consensus in a majority $\mathrm{D}^{*}$ of elements of $\mathrm{D}$, total consensus means that there is consensus in D.

A procedure to activate consensus is a procedure based on movements of points $\mathrm{P}_{\mathrm{r}}$, following a set of rules and algorithms, with the aim to obtain consensus in the maximum possible subset $\mathrm{D}^{*}$ of $\mathrm{D}$. If the final set $\mathrm{D}^{*}$ is a majority we say that the consensus is obtained, otherwise we say that consensus is not achievable. Some of these procedures are in (Carlsson, et al., 1992; Eklund, et al., 2007; Maturo, and Ventre, 2008).

For instance, in the above mentioned framework, let us introduce the following procedure:

(a) at step $\mathrm{p}$ (p positive integer), if there is total consensus, then the position of the points $\mathrm{P}_{\mathrm{r}}$ is the final position and the procedure ends;

(b) at step $\mathrm{p}$, if the consensus is not total, a maximal consensus set $\mathrm{D}^{*}$ is chosen (according to given rules) and the decision makers whose representative points are not in $\mathrm{D}^{*}$ are invited, one by one, to control and eventually change their assessments of weights of criteria, and scores of alternatives with the aim to obtain a consensus set with greater cardinality than $\mathrm{D}^{*}$. The step ends if a consensus set more numerous than $\mathrm{D}^{*}$ is obtained, or each invited decision maker either moved or refused to move.

(c) if, in a fixed number $\mathrm{h}$ of steps, the number of elements of a maximal consensus set does not increase, then the procedure ends. At this point, if the maximal consensus sets are not majorities, then the consensus is considered not achievable, otherwise a maximal majority and consensus set $\mathrm{D}^{*}$ is chosen (according to given rules) and, in order to ranking alternatives, aggregation of scores of elements of $\mathrm{D}^{*}$ is made.

\subsection{Movements of decision makers as corrections in the AHP procedure}

Let scores be real numbers and the aggregation function be the sum. Then the i-th coordinate of the point $\mathrm{P}_{\mathrm{r}}$ is the scalar product $\sigma_{\mathrm{i}}{ }^{(\mathrm{r})}$ of the vectors of weights of criteria, $\mathrm{w}^{(\mathrm{r})}=\left(\mathrm{w}_{1}{ }^{(\mathrm{r})}, \mathrm{w}_{2}{ }^{(\mathrm{r})}, \ldots, \mathrm{w}_{\mathrm{n}}{ }^{(\mathrm{r})}\right)$ and the vector of the scores of the alternative $A_{i}, s_{i}{ }^{(r)}=\left(s_{i 1}{ }^{(r)}, s_{i 2}{ }^{(r)}, \ldots, s_{i n}{ }^{(r)}\right)$, respectively, in the opinion of $d_{r}$, i.e.,

$$
\sigma_{\mathrm{i}}^{(\mathrm{r})}=\mathrm{W}_{1}{ }^{(\mathrm{r})} \mathrm{s}_{\mathrm{i} 1}{ }^{(\mathrm{r})}+\mathrm{W}_{2}{ }^{(\mathrm{r})} \mathrm{s}_{\mathrm{i} 2}{ }^{(\mathrm{r})}+\ldots+\mathrm{W}_{\mathrm{n}}{ }^{(\mathrm{r})} \mathrm{s}_{\mathrm{in}}{ }^{(\mathrm{r})}
$$

Then the value $\sigma_{i}^{(r)}=\left\|w^{(r)}\right\|\left\|s_{i}{ }^{(r)}\right\| \cos \left(w^{(r)}, s_{i}{ }^{(r)}\right)$ depends on the norms of $s_{i}{ }^{(r)}, w^{(r)}$ and the angle between the two vectors. The less is the angle, the greater is the $\mathrm{i}$-th coordinate of $\mathrm{P}_{\mathrm{r}}$.

In order to obtain a consensus of $d_{r}$ with a group of decision makers $\left\{d_{s}, s \in S \subseteq D\right\}$, the Demiurge may ask $d_{r}$ to control if a revision of his judgments is able to move $\sigma_{i}^{(r)}$ closer to the interval $\left[\min _{s} \sigma_{i}^{(s)}\right.$, $\left.\max _{s} \sigma_{i}^{(s)}\right]$.

For instance, if $\sigma_{\mathrm{i}}^{(\mathrm{r})}<\min _{\mathrm{s}} \sigma_{\mathrm{i}}^{(\mathrm{s})}$, than, if we wish increase $\cos \left(\mathrm{w}^{(\mathrm{r})}, \mathrm{s}_{\mathrm{i}}{ }^{(\mathrm{r})}\right)$ without change $\mathrm{w}^{(\mathrm{r})}$ or $\left\|\mathrm{s}_{\mathrm{i}}{ }^{(\mathrm{r})}\right\|$, we must rotate the vector $\mathrm{s}_{\mathrm{i}}{ }^{(\mathrm{r})}$ in such a way that its representative segment, with the origin at the point $\mathrm{O}=(0$, 
$0, \ldots, 0)$ of $\mathrm{R}^{\mathrm{n}}$, moves to the interior of the hypercone with vertex $\mathrm{O}$, axis parallel to $\mathrm{w}^{(\mathrm{r})}$, and angle $\left(\mathrm{w}^{(\mathrm{r})}\right.$, $\left.\mathrm{s}_{\mathrm{i}}^{(\mathrm{r})}\right)$. Analogously, if we wish increase $\cos \left(\mathrm{w}^{(\mathrm{r})}, \mathrm{s}_{\mathrm{i}}^{(\mathrm{r})}\right)$ without change $\mathrm{s}_{\mathrm{i}}^{(\mathrm{r})}$ and $\left\|\mathrm{w}^{(\mathrm{r})}\right\|$, we must rotate the vector $\mathrm{w}^{(\mathrm{r})}$ in such a way that its representative segment with the origin at the point $\mathrm{O}=(0,0, \ldots, 0)$ of $\mathrm{R}^{\mathrm{n}}$, moves to the interior of the hypercone with vertex $\mathrm{O}$, axis parallel to $\mathrm{s}_{\mathrm{i}}^{(\mathrm{r})}$, and angle $\left(\mathrm{w}^{(\mathrm{r})}, \mathrm{s}_{\mathrm{i}}{ }^{(\mathrm{r})}\right)$. Practically, $\cos \left(\mathrm{w}^{(\mathrm{r})}, \mathrm{s}_{\mathrm{i}}^{(\mathrm{r})}\right)$ is increasing if the modification of judgments of $\mathrm{d}_{\mathrm{r}}$ has the consequence that in (3.7) the larger components of $\mathrm{w}^{(\mathrm{r})}$ are multiplied by the larger components of $\mathrm{s}_{\mathrm{i}}^{(\mathrm{r})}$.

A more complete treatment of the revision of decision makers judgments leads to solve systems of linear equations and inequalities (Carlsson et al, 1992).

From the graph theoretical point of view, the AHP procedure considers a directed graph G, precisely a hierarchical graph; the orientation of the arcs goes from higher to smaller levels. The vertex L represents the overall goal, and the final vertices the alternatives. A final arc $(i, j)$ is that having as first vertex the criterion $\mathrm{K}_{\mathrm{i}}$ and final vertex the alternative $\mathrm{A}_{\mathrm{j}}$. With the AHP procedure a nonnegative real number is associated to every arc, with the condition that, for every vertex $\mathrm{V}$, the sum of the numbers associated to the arcs with first vertex $\mathrm{V}$ is equal to 1 .

For every path $\mathrm{P}$, the score of $\mathrm{P}$ is defined as the product of the numbers associated to the arcs belonging to $\mathrm{P}$. Moreover, for every $\mathrm{V} \neq \mathrm{L}$, the paths associated to $\mathrm{V}$ are the paths starting from $\mathrm{L}$ and having $\mathrm{V}$ as the final vertex. The score of $\mathrm{V}$ is defined as the sum of the scores of all the paths associated to $\mathrm{V}$.

In particular, in this way, we obtain the scores of the criteria and of the alternatives.

In the set of paths associated to alternatives, we can define critical paths the ones having maximal scores. In order to reaching consensus, every decision maker $d_{s}$ not belonging to a consensus set, can be invited by the Demiurge to put particular attention to his critical paths. Modifications even small of the scores of some arcs in these paths, may get the compromise of maintaining the coherence with the opinion of $d_{s}$, and leading $\mathrm{d}_{\mathrm{s}}$ very close to a consensus set.

\section{Aggregation of experts opinions and ranking of the alternatives}

Let us suppose that, with one of the above algorithms, the Demiurge individuates a maximal consensus set and majority $\mathrm{D}^{*}=\left\{\mathrm{d}_{1}, \mathrm{~d}_{2}, \ldots, \mathrm{d}_{\mathrm{h}}\right\}, \mathrm{h} \leq \mathrm{k}$, having the task to ranking alternatives. We assume also that, by means of the AHP procedure, for every component $d_{r}$ of $D^{*}$, a degree of importance $\delta_{r}$ is assigned, with the conditions:

$$
0 \leq \delta_{\mathrm{r}} \leq 1 \text { and } \delta_{1}+\delta_{2}+\ldots+\delta_{\mathrm{h}}=1 \text {. }
$$

For instance, the decision makers can be representatives of social or political groups and the degree of importance of $d_{r}$ depends on the strength of the group represented by $d_{r}$. In many circumstances can be accepted that decision makers have the same importance and then every $\delta_{\mathrm{r}}$ is equal to $1 / \mathrm{h}$.

A usual procedure to aggregate opinions of the components of $\mathrm{D}^{*}$, and then obtain a global score $\sigma\left(\mathrm{A}_{\mathrm{i}}\right)$ for every alternative $A_{i}$, is to calculate the weighed arithmetic mean:

$$
\sigma\left(A_{i}\right)=\delta_{1} \sigma_{i}^{(1)}+\delta_{2} \sigma_{i}^{(2)}+\ldots+\delta_{h} \sigma_{i}^{(h)} .
$$

Formula (4.2) does not consider the degree of consensus among the elements of $\mathrm{D}^{*}$ on the global scores $\sigma_{i}^{(r)}$ assigned to the alternative $A_{i}$. Then we propose to consider also a dispersion index $\mu\left(A_{i}\right)$ of such scores as a number belonging to the interval $[0,1]$, null if the $\sigma_{i}^{(r)}$ are all equal to the same number, and increasing if the absolute values of differences among the $\sigma_{i}^{(r)}$ are increasing.

Finally, in order to take in account the arithmetic mean of scores and the degree of consensus, we suggest that the real numbers $\sigma\left(\mathrm{A}_{\mathrm{i}}\right)$ can be replaced by the triangular fuzzy numbers $\sigma^{*}\left(\mathrm{~A}_{\mathrm{i}}\right)$, defined as follows: 


$$
\sigma^{*}\left(A_{i}\right)=\left(\sigma\left(A_{i}\right)-\mu\left(A_{i}\right), \sigma\left(A_{i}\right), \sigma\left(A_{i}\right)+\mu\left(A_{i}\right)\right) .
$$

A problem arising by formula (4.3) is the possibility that the supports of the fuzzy numbers $\sigma^{*}\left(\mathrm{~A}_{\mathrm{i}}\right)$ may not be contained in the interval $[0,1]$. A solution to this problem can be obtained by considering a strict tconorm $\oplus$, and then replacing, in (4.3), $\sigma\left(\mathrm{A}_{\mathrm{i}}\right)+\mu\left(\mathrm{A}_{\mathrm{i}}\right)$ with $\sigma\left(\mathrm{A}_{\mathrm{i}}\right) \oplus \mu\left(\mathrm{A}_{\mathrm{i}}\right)$, and the difference $\sigma\left(\mathrm{A}_{\mathrm{i}}\right)-\mu\left(\mathrm{A}_{\mathrm{i}}\right)$ with the number $\sigma\left(A_{i}\right) \sim \mu\left(A_{i}\right)$, defined as the solution $x_{i}$ of the equation $x_{i} \oplus \mu\left(A_{i}\right)=\sigma\left(A_{i}\right)$ if $\mu\left(A_{i}\right) \leq$ $\sigma\left(\mathrm{A}_{\mathrm{i}}\right)$, and equal to 0 if $\mu\left(\mathrm{A}_{\mathrm{i}}\right) \geq \sigma\left(\mathrm{A}_{\mathrm{i}}\right)$.

\section{Concluding remarks. A case study}

We assumed throughout the whole paper that any expert makes use of AHP system. Moreover, a unique hierarchical scheme is imposed to the committee, or the committee has self-imposed this scheme, that has a fixed overall goal at level 1 , fixed criteria at level 2 , possible sub-criteria at the following levels, and a common set of alternatives. The freedom to assign weights over the paths, ending on the alternatives, is left to any expert. However, freedom has a limitation given by the mission to reach consensus. Furthermore, reaching consensus may happen under the possible intervention of the chairman. Of course, as we have seen in Sec.1, the process above starts if the experts share the same explicative paradigm.

Let us now consider a simple case study. Suppose that a committee is constituted with the aim to activate an improvement of the conditions of a city. This task has to be detailed and clarified to any expert, in particular a set of operational criteria is provided and a set of alternatives to rank.

We just observe that such a task is, of course, strictly related with the historical, social, territorial, context; then the criteria, informing the action of the committee, must be coherent with the context. At a first look, it is hard nowadays to accept the basic principles dictated by Thomas Campanella for the creation of the ideal city (Campanella $T$., 1602): there the general criteria at the second level were fixed by the Author as: Power (defense, army), Knowledge, and Love (including social issues), with peculiar meanings. Nowadays a reasonable and recognized scheme of action in urban planning, social project, heritage, environment has the overall goal (Fusco Girard L., and Nijkamp P., 1997) in the

\section{sustainability of the development (level 1)}

and general criteria are (level 2):

- $\mathrm{K}_{1}=$ economical efficiency,

- $\mathrm{K}_{2}=$ social equity,

- $\mathrm{K}_{3}=$ environment preservation.

In our simplified case study, the alternatives to be ranked (level 3), that imply the intensities of the directions of the actions, are:

- $\mathrm{A}_{1}=$ business city,

- $\mathrm{A}_{2}=$ tourist city,

- $\mathrm{A}_{3}=$ green city,

- $\mathrm{A}_{4}=$ university city.

A committee of three members is constituted and the experts are: 
- a general manager $\left(\mathrm{d}_{1}\right)$,

- a town planner $\left(\mathrm{d}_{2}\right)$,

- a geologist $\left(\mathrm{d}_{3}\right)$.

The general manager $\left(d_{1}\right)$ assigns to the criteria at level 2 the following scores:

\subsection{5 to economical efficiency; \\ 0.35 to social equity;}

0.30 to environment preservation.

The pairwise comparisons matrices of the general manager, under each criterion, are as follows:

\begin{tabular}{|c|c|c|c|c|}
\hline $\mathbf{K}_{1}$ & $\mathbf{A}_{1}$ & $\mathbf{A}_{2}$ & $\mathbf{A}_{3}$ & $\mathbf{A}_{4}$ \\
\hline $\mathbf{A}_{1}$ & $\mathbf{1}$ & $\mathbf{3}$ & $\mathbf{2}$ & $\mathbf{1} / \mathbf{2}$ \\
\hline $\mathbf{A}_{2}$ & $\mathbf{1} / \mathbf{3}$ & $\mathbf{1}$ & $\mathbf{1}$ & $\mathbf{1}$ \\
\hline $\mathbf{A}_{3}$ & $\mathbf{1}$ & $\mathbf{1}$ & $\mathbf{1}$ & $\mathbf{2}$ \\
\hline $\mathbf{A}_{4}$ & $\mathbf{2}$ & $\mathbf{1}$ & $\mathbf{1} / \mathbf{2}$ & $\mathbf{1}$ \\
\hline
\end{tabular}

Matrix 1 (pairwise comparisons under criterion $K_{1}$ )

\begin{tabular}{|c|c|c|c|c|}
\hline $\mathbf{K}_{2}$ & $\mathbf{A}_{\mathbf{1}}$ & $\mathbf{A}_{\mathbf{2}}$ & $\mathbf{A}_{\mathbf{3}}$ & $\mathbf{A}_{\mathbf{4}}$ \\
\hline $\mathbf{A}_{\mathbf{1}}$ & $\mathbf{1}$ & $\mathbf{2}$ & $\mathbf{2}$ & $\mathbf{1}$ \\
\hline $\mathbf{A}_{2}$ & $\mathbf{1} / \mathbf{2}$ & $\mathbf{1}$ & $\mathbf{1}$ & $\mathbf{1}$ \\
\hline $\mathbf{A}_{3}$ & $\mathbf{1} / \mathbf{2}$ & $\mathbf{1}$ & $\mathbf{1}$ & $\mathbf{1}$ \\
\hline $\mathbf{A}_{\mathbf{4}}$ & $\mathbf{1}$ & $\mathbf{1}$ & $\mathbf{1}$ & $\mathbf{1}$ \\
\hline
\end{tabular}

Matrix 2 (pairwise comparisons under criterion $K_{2}$ )

\begin{tabular}{|c|c|c|c|c|}
\hline $\mathbf{K}_{3}$ & $\mathbf{A}_{\mathbf{1}}$ & $\mathbf{A}_{2}$ & $\mathbf{A}_{3}$ & $\mathbf{A}_{\mathbf{4}}$ \\
\hline $\mathbf{A}_{1}$ & $\mathbf{1}$ & $\mathbf{1}$ & $\mathbf{1}$ & $\mathbf{5}$ \\
\hline $\mathbf{A}_{2}$ & $\mathbf{1}$ & $\mathbf{1}$ & $\mathbf{1}$ & $\mathbf{3}$ \\
\hline $\mathbf{A}_{3}$ & $\mathbf{1}$ & $\mathbf{1}$ & $\mathbf{1}$ & $\mathbf{3}$ \\
\hline $\mathbf{A}_{4}$ & $\mathbf{1} / \mathbf{5}$ & $\mathbf{1} / \mathbf{3}$ & $\mathbf{1 / 3}$ & $\mathbf{1}$ \\
\hline
\end{tabular}

Matrix 3 (pairwise comparisons under criterion $K_{3}$ )

The maximum eigenvalue $\lambda_{\max }$, the consistency index $\mu$, and the correspondent normalized eigenvector $\mathrm{v}$ for each matrix 1, 2, 3, respectively, are shown in the following table 1:

\begin{tabular}{|c|c|c|c|}
\hline general manager & $\lambda_{\max }$ & $\mu$ & $v$ \\
\hline Matrix 1 & 4.546 & $\mathbf{0 . 1 8 2}$ & $(\mathbf{0 . 3 2 0}, \mathbf{0 . 1 7 3}, \mathbf{0 . 2 4 3}, \mathbf{0 . 2 6 4})$ \\
\hline Matrix 2 & 4.061 & $\mathbf{0 . 0 2 0}$ & $(\mathbf{0 . 3 4 7 , 0 . 2 0 4 , 0 . 2 0 4 , 0 . 2 4 6 )}$ \\
\hline Matrix 3 & 4.033 & $\mathbf{0 . 0 1 1}$ & $(\mathbf{0 . 3 3 3 , 0 . 2 9 1 , 0 . 2 9 1 , 0 . 0 8 6 )}$ \\
\hline
\end{tabular}

Table 1

The global scores of the alternatives, with respect to $d_{1}$, are:

$$
\begin{aligned}
& \sigma_{1}{ }^{(1)}=(0.35,0.35,0.30)(0.320,0.347,0.333)=0.333 \\
& \sigma_{2}{ }^{(1)}=(0.35,0.35,0.30)(0.173,0.204,0.291)=0.219 \\
& \sigma_{3}{ }^{(1)}=(0.35,0.35,0.30)(0.243,0.204,0.291)=0.244 \\
& \sigma_{4}{ }^{(1)}=(0.35,0.35,0.30)(0.264,0.246,0.086)=0.204
\end{aligned}
$$


The town planner $\left(d_{2}\right)$ assigns to the criteria at level 2 the following scores:

\subsection{0 to economical efficiency; \\ 0.35 to social equity; \\ 0.35 to environment preservation.}

The pairwise comparisons matrices of the town planner, under each criterion, are as follows:

\begin{tabular}{|c|c|c|c|c|}
\hline $\mathbf{K}_{1}$ & $\mathbf{A}_{1}$ & $\mathbf{A}_{2}$ & $\mathbf{A}_{3}$ & $\mathbf{A}_{4}$ \\
\hline $\mathbf{A}_{1}$ & $\mathbf{1}$ & $\mathbf{1} / \mathbf{2}$ & $\mathbf{1} / \mathbf{2}$ & $\mathbf{1}$ \\
\hline $\mathbf{A}_{2}$ & $\mathbf{2}$ & $\mathbf{1}$ & $\mathbf{1}$ & $\mathbf{1}$ \\
\hline $\mathbf{A}_{3}$ & $\mathbf{2}$ & $\mathbf{1}$ & $\mathbf{1}$ & $\mathbf{2}$ \\
\hline $\mathbf{A}_{4}$ & $\mathbf{1}$ & $\mathbf{1}$ & $\mathbf{1} / \mathbf{2}$ & $\mathbf{1}$ \\
\hline
\end{tabular}

Matrix 4 (pairwise comparisons under criterion $K_{1}$ )

\begin{tabular}{|c|c|c|c|c|}
\hline $\mathbf{K}_{2}$ & $\mathbf{A}_{\mathbf{1}}$ & $\mathbf{A}_{2}$ & $\mathbf{A}_{3}$ & $\mathbf{A}_{\mathbf{4}}$ \\
\hline $\mathbf{A}_{1}$ & $\mathbf{1}$ & $\mathbf{1} / \mathbf{3}$ & $\mathbf{1}$ & $\mathbf{1} / \mathbf{2}$ \\
\hline $\mathbf{A}_{2}$ & $\mathbf{3}$ & $\mathbf{1}$ & $\mathbf{1}$ & $\mathbf{1} / \mathbf{2}$ \\
\hline $\mathbf{A}_{3}$ & $\mathbf{1}$ & $\mathbf{1}$ & $\mathbf{1}$ & $\mathbf{1} / \mathbf{2}$ \\
\hline $\mathbf{A}_{4}$ & $\mathbf{2}$ & $\mathbf{2}$ & $\mathbf{2}$ & $\mathbf{1}$ \\
\hline
\end{tabular}

Matrix 5 (pairwise comparisons under criterion $K_{2}$ )

\begin{tabular}{|c|c|c|c|c|}
\hline $\mathbf{K}_{3}$ & $\mathbf{A}_{1}$ & $\mathbf{A}_{2}$ & $\mathbf{A}_{3}$ & $\mathbf{A}_{4}$ \\
\hline $\mathbf{A}_{1}$ & $\mathbf{1}$ & $\mathbf{1} / \mathbf{2}$ & $\mathbf{1} / \mathbf{2}$ & $\mathbf{1 / 2}$ \\
\hline $\mathbf{A}_{2}$ & $\mathbf{2}$ & $\mathbf{1}$ & $\mathbf{1}$ & $\mathbf{1}$ \\
\hline $\mathbf{A}_{3}$ & $\mathbf{2}$ & $\mathbf{1}$ & $\mathbf{1}$ & $\mathbf{1} / \mathbf{2}$ \\
\hline $\mathbf{A}_{4}$ & $\mathbf{2}$ & $\mathbf{1}$ & $\mathbf{2}$ & $\mathbf{1}$ \\
\hline
\end{tabular}

Matrix 6 (pairwise comparisons under criterion $K_{3}$ )

The maximum eigenvalue $\lambda_{\max }$, the consistency index $\mu$, and the correspondent normalized eigenvector $v$ for each matrix $1,2,3$, respectively, are shown in the following table 2 :

\begin{tabular}{|c|c|c|c|}
\hline town planner & $\lambda_{\max }$ & $\mu$ & $v$ \\
\hline Matrix 4 & 4.061 & $\mathbf{0 . 0 2 0}$ & $(\mathbf{0 . 1 6 9 , 0 . 2 8 8 , 0 . 3 3 8 , 0 . 2 0 5 )}$ \\
\hline Matrix 5 & 4.154 & $\mathbf{0 . 0 5 2}$ & $(\mathbf{0 . 1 5 1 , 0 . 2 6 7 , 0 . 1 9 4 , 0 . 3 8 8 )}$ \\
\hline Matrix 6 & 4.061 & $\mathbf{0 . 0 2 0}$ & $(\mathbf{0 . 1 4 0 , 0 . 2 8 1 , 0 . 2 3 9 , 0 . 3 4 0 )}$ \\
\hline
\end{tabular}

Table 2

The global scores of the alternatives, with respect to $d_{2}$, are:

$$
\begin{aligned}
& \sigma_{1}{ }^{(2)}=(0.30,0.35,0.35)(0.169,0.151,0.140)=0.153 \\
& \sigma_{2}{ }^{(2)}=(0.30,0.35,0.35)(0.288,0.267,0.281)=0.278 \\
& \sigma_{3}{ }^{(2)}=(0.30,0.35,0.35)(0.338,0.194,0.239)=0.253 \\
& \sigma_{4}^{(2)}=(0.30,0.35,0.35)(0.205,0.388,0.340)=0.316
\end{aligned}
$$


The geologist $\left(\mathrm{d}_{3}\right)$ assigns to the criteria at level 2 the following scores:

\subsection{5 to economical efficiency; \\ 0.35 to social equity; \\ 0.40 to environment preservation}

The pairwise comparisons matrices of the geologist, under each criterion, are as follows:

\begin{tabular}{|c|c|c|c|c|}
\hline $\mathbf{K}_{1}$ & $\mathbf{A}_{1}$ & $\mathbf{A}_{2}$ & $\mathbf{A}_{3}$ & $\mathbf{A}_{4}$ \\
\hline $\mathbf{A}_{1}$ & $\mathbf{1}$ & $\mathbf{1} / \mathbf{2}$ & $\mathbf{1 / 5}$ & $\mathbf{1 / 2}$ \\
\hline $\mathbf{A}_{2}$ & $\mathbf{2}$ & $\mathbf{1}$ & $\mathbf{1} / \mathbf{2}$ & $\mathbf{1}$ \\
\hline $\mathbf{A}_{3}$ & $\mathbf{5}$ & $\mathbf{2}$ & $\mathbf{1}$ & $\mathbf{1}$ \\
\hline $\mathbf{A}_{4}$ & $\mathbf{2}$ & $\mathbf{1}$ & $\mathbf{1}$ & $\mathbf{1}$ \\
\hline
\end{tabular}

Matrix 7 (pairwise comparisons under criterion $K_{1}$ )

\begin{tabular}{|c|c|c|c|c|}
\hline $\mathbf{K}_{2}$ & $\mathbf{A}_{\mathbf{1}}$ & $\mathbf{A}_{2}$ & $\mathbf{A}_{3}$ & $\mathbf{A}_{4}$ \\
\hline $\mathbf{A}_{1}$ & $\mathbf{1}$ & $\mathbf{1} / \mathbf{2}$ & $\mathbf{1} / \mathbf{6}$ & $\mathbf{1 / 3}$ \\
\hline $\mathbf{A}_{2}$ & $\mathbf{2}$ & $\mathbf{1}$ & $\mathbf{1} / \mathbf{2}$ & $\mathbf{1}$ \\
\hline $\mathbf{A}_{3}$ & $\mathbf{6}$ & $\mathbf{2}$ & $\mathbf{1}$ & $\mathbf{1}$ \\
\hline $\mathbf{A}_{\mathbf{4}}$ & $\mathbf{3}$ & $\mathbf{1}$ & $\mathbf{1}$ & $\mathbf{1}$ \\
\hline
\end{tabular}

Matrix 8 (pairwise comparisons under criterion $K_{2}$ )

\begin{tabular}{|c|c|c|c|c|}
\hline $\mathbf{K}_{3}$ & $\mathbf{A}_{1}$ & $\mathbf{A}_{2}$ & $\mathbf{A}_{3}$ & $\mathbf{A}_{4}$ \\
\hline $\mathbf{A}_{1}$ & $\mathbf{1}$ & $\mathbf{1} / 3$ & $\mathbf{1} / \mathbf{5}$ & $\mathbf{1 / 5}$ \\
\hline $\mathbf{A}_{2}$ & $\mathbf{3}$ & $\mathbf{1}$ & $\mathbf{1} / \mathbf{2}$ & $\mathbf{1}$ \\
\hline $\mathbf{A}_{3}$ & $\mathbf{5}$ & $\mathbf{2}$ & $\mathbf{1}$ & $\mathbf{2}$ \\
\hline $\mathbf{A}_{4}$ & $\mathbf{5}$ & $\mathbf{1}$ & $\mathbf{1} / \mathbf{2}$ & $\mathbf{1}$ \\
\hline
\end{tabular}

Matrix 9 (pairwise comparisons under criterion $K_{3}$ )

The maximum eigenvalue $\lambda_{\max }$, the consistency index $\mu$, and the correspondent normalized eigenvector $v$ for each matrix $1,2,3$, respectively, are shown in the following table 3:

\begin{tabular}{|c|c|c|c|}
\hline geologist & $\lambda_{\max }$ & $\mu$ & $v$ \\
\hline Matrix 7 & 4.087 & $\mathbf{0 . 0 2 9}$ & $(\mathbf{0 . 1 0 6 , 0 . 2 2 1 , 0 . 4 0 2 , 0 . 2 7 1 )}$ \\
\hline Matrix 8 & 4.081 & $\mathbf{0 . 0 2 7}$ & $\mathbf{( 0 . 0 8 8 , 0 . 2 1 7 , 0 . 4 0 6 , 0 . 2 8 8 )}$ \\
\hline Matrix 9 & 4.049 & $\mathbf{0 . 0 1 6}$ & $(\mathbf{0 . 0 7 1 , 0 . 2 2 8 , 0 . 4 3 8 , 0 . 2 6 3 )}$ \\
\hline
\end{tabular}

Table 3

The global scores of the alternatives, with respect to $d_{3}$, are:

$$
\begin{aligned}
& \sigma_{1}^{(3)}=(0.25,0.35,0.40)(0.106,0.088,0.071)=0.086 \\
& \sigma_{2}{ }^{(3)}=(0.25,0.35,0.40)(0.221,0.217,0.228)=0.222 \\
& \sigma_{3}{ }^{(3)}=(0.25,0.35,0.40)(0.402,0.406,0.438)=0.418 \\
& \sigma_{4}{ }^{(3)}=(0.25,0.35,0.40)(0.271,0.288,0.263)=0.274
\end{aligned}
$$


In the following table 4 we show the positions of all the experts in the space of alternatives, the absolute values of the differences of the coordinates, and the pairwise Euclidean distances.

\begin{tabular}{|c|c|c|c|c|c|c|}
\hline $\mathbf{R}^{4}$ & $\mathbf{P}_{1}$ & $\mathbf{P}_{\mathbf{2}}$ & $\mathbf{P}_{\mathbf{3}}$ & $\boldsymbol{\mu}_{12}$ & $\boldsymbol{\mu}_{13}$ & $\boldsymbol{\mu}_{23}$ \\
\hline $\mathbf{A}_{\mathbf{1}}$ & $\mathbf{0 . 3 3 3}$ & $\mathbf{0 . 1 5 3}$ & $\mathbf{0 . 0 8 6}$ & $\mathbf{0 . 1 8 0}$ & $\mathbf{0 . 2 4 7}$ & $\mathbf{0 . 0 6 7}$ \\
\hline $\mathbf{A}_{\mathbf{2}}$ & $\mathbf{0 . 2 1 9}$ & $\mathbf{0 . 2 7 8}$ & $\mathbf{0 . 2 2 2}$ & $\mathbf{0 . 0 5 9}$ & $\mathbf{0 . 0 0 3}$ & $\mathbf{0 . 0 5 6}$ \\
\hline $\mathbf{A}_{3}$ & $\mathbf{0 . 2 4 4}$ & $\mathbf{0 . 2 5 3}$ & $\mathbf{0 . 4 1 8}$ & $\mathbf{0 . 0 0 9}$ & $\mathbf{0 . 1 7 4}$ & $\mathbf{0 . 1 6 5}$ \\
\hline $\mathbf{A}_{4}$ & $\mathbf{0 . 2 0 4}$ & $\mathbf{0 . 3 1 6}$ & $\mathbf{0 . 2 7 4}$ & $\mathbf{0 . 1 1 2}$ & $\mathbf{0 . 0 7 0}$ & $\mathbf{0 . 0 4 2}$ \\
\hline $\begin{array}{c}\text { Euclidean } \\
\text { distance }\end{array}$ & & & & $\mathbf{0 . 2 2 0}$ & $\mathbf{0 . 3 3 2}$ & $\mathbf{0 . 1 9 2}$ \\
\hline
\end{tabular}

Table 4

Let us suppose that the consensus is required at level 0.8 , i.e., a consensus set is a set of experts with pairwise distances not greater than 0.2 . In this case experts $d_{2}$ and $d_{3}$ (the town planner and the geologist) form a consensus set that is a majority. While the general manager $d_{1}$ is peripheral. Then the Demiurge asks him to modify his opinions in order to move in a consensus set. For instance, after a look at table 4, the general manager can diminish scores of paths associated to $A_{1}$ and increase scores associated to $A_{2}$ and $A_{4}$. In such a way he approaches $d_{2}$ and distance $\mu_{12}$ may become less than $\mu_{23}$. At this point the geologist $d_{3}$ becomes the more peripheral among the experts, and dynamics continues.

\section{REFERENCES}

Carlsson C., Ehrenberg D., Eklund P., Fedrizzi M., Gustafsson P., Lindholm P., Merkurieva G., Riissanen T., \& Ventre A. G. S., (1992). Consensus in distributed soft environments, European J. Operational Research 61, 165-185.

Campanella T., (1602), La Città del Sole, (in Italian); Civitas Solis, Idea Reipublicae Philosophicae, Frankfurt, 1623, (in Latin).

Eklund P., Rusinowska A., \& De Swart H., (2007). Consensus reaching in committees, European Journal of Operational Research 178, 185-193.

Feyerabend, P., (1975). Against method, Humanities Press, Atlantic Highlands, N. J.

Fusco Girard L., \& Nijkamp P., (1997), Le valutazioni per lo sviluppo sostenibile della città e del territorio, Franco Angeli, Milano, (in Italian)

Herrera-Viedma E., Alonso S., Chiclana F., \& Herrera F., (2007), A Consensus Model for Group Decision Making with Incomplete Fuzzy Preference Relations, IEEE Transactions on Systems Fuzzy Systems 15, 5, 863-877.

Klir G.J., \& Yuan B., (1995), Fuzzy sets and fuzzy logic, Prentice Hall, N. Jersey

Luce, R. D., \& Raiffa, H., (1957), Games and Decisions, John Wiley, New York.

Mares, M., Fuzzy Cooperative Games, (2001), Springer Verlag, New York.

Maturo A., Squillante M., \& Ventre A. G. S., (2006), Consistency for non additive measures: analytical and algebraic methods. In: B. Reusch, Computational Intelligence, Theory and Applications, SpringerVerlag, Berlin, 29-40. 
Maturo, A., \& Ventre, A. G. S., (2008). Models for Consensus in Multiperson Decision Making, NAFIPS Conference Proceedings 08, IEEE Press, New York, USA.

Saaty, T. L., (1980) The Analytic Hierarchy Process, McGraw-Hill, New York.

Saaty, T. L., \& Peniwati, K. (2007). Group decision-making: Drawing out and reconciling differences. Pittsburgh, PA: RWS Publications.

Saaty, T. L., \& Shang, J.S. (2007). Group decision-making: Head-count versus intensity of preference. Socio-Economic Planning Sciences, 41, 22-37.

Saaty, T. L., (2008). Relative Measurement and Its Generalization in Decision Making. Why Pairwise Comparisons are Central in Mathematics for the Measurement of Intangible Factors. The Analytic Hierarchy/Network Process, Rev. R. Acad. Cien. Serie A. Mat., Vol. 102 (2), 251-318.

Sciarra E., (2006), Motivi e sviluppi dell'epistemologia contemporanea, Libreria Universitaria Editrice, Pescara, Italy (in Italian).

Shapley, L. S., (1962), Simple games. An outline of the theory, Behavioral Sciences 7, 59-66.

Shapley, L. S., (1953), A value for n-person games, Annals of Mathematics Studies No 28, 307-317, Princeton University.

Weber, S., (1984), Decomposable measures and integrals for Archimedean t-conorms, J. Math. Anal. Appl. 101 (1), 114-138.

Zadeh, L., (1975a), The Concept of a Linguistic Variable and its Application to Approximate Reasoning I and II, Information Sciences, 8, p. 199-249 and p. 301-357.

Zadeh, L., (1975b), The Concept of a Linguistic Variable and its Applications to Approximate reasoning III, Information Sciences 9, p. 43-80. 